Volume 6

\title{
Threat of Technological Unemployment, Use Intentions, and the Promotion of Structured Interviews in Personnel Selection
}

\author{
Kevin P. Nolan \\ Hofstra University \\ Dev K. Dalal \\ University at Albany, State University of New York \\ Nathan Carter \\ University of Georgia
}

Follow this and additional works at: https://scholarworks.bgsu.edu/pad

Part of the Business Administration, Management, and Operations Commons, Human Resources Management Commons, Industrial and Organizational Psychology Commons, Organizational Behavior and Theory Commons, and the Other Psychology Commons

How does access to this work benefit you? Let us know!

\section{Recommended Citation}

Nolan, Kevin P.; Dalal, Dev K.; and Carter, Nathan (2020) "Threat of Technological Unemployment, Use Intentions, and the Promotion of Structured Interviews in Personnel Selection," Personnel Assessment and Decisions: Number 6 : Iss. 2 , Article 6. DOI: https://doi.org/10.25035/pad.2020.02.006

Available at: https://scholarworks.bgsu.edu/pad/vol6/iss2/6

This Main Article is brought to you for free and open access by the Journals at ScholarWorks@BGSU. It has been accepted for inclusion in Personnel Assessment and Decisions by an authorized editor of ScholarWorks@BGSU. 


\title{
Threat of TeChnological Unemployment, Use Intentions, AND the Promotion of Structured Interviews in Personnel Selection
}

\author{
Kevin P. Nolan', Dev K. Dalal' ${ }^{2}$, and Nathan Carter ${ }^{3}$
}

1. Hofstra University

2. University at Albany, State University of New York

3. University of Georgia

ABSTRACT

Meehl (1986) proposed that an important factor underlying professional decision makers' resistance to standardized decision aids is threat of technological unemployment - fear that using the practices would reduce the perceived value of their employment. Nolan, Carter, and Dalal (2016) provided initial support for threat of technological unemployment being a factor that contributes to practitioners' reluctance to adopt scientifically meritorious standardized hiring practices. This study serves to further develop the theory of threat of technological unemployment in personnel selection by (a) replicating the findings of our earlier research using a within-subjects methodology that is more generalizable to the cognitive processes typically involved in decisions concerning the adoption of standardized hiring practices, and (b) examining if techniques that are commonly used to promote standardized hiring practices inadvertently exacerbate the threat. Results suggest that communicating the utility of standardization affects threat of technological unemployment but not in the ways expected.

personnel selection, employment interview, structured interview, standardized decision making, threat of technological unemployment, attributions
A well-documented gap exists between research on personnel selection and its practice in organizations (Rynes, 2012). Whereas research strongly supports the use of standardized data collection methods that evaluate job candidates via uniform assessment formats and formal rating scales, practitioners continue to prefer more subjective, intuition-based approaches to hiring (Highhouse, 2008). Research, for example, has consistently demonstrated that structured employment interviews have greater reliability and predictive validity, and result in less subgroup differences than unstructured interviews (Conway et al., 1995; Huffcutt \& Arthur, 1994; Huffcutt \& Roth, 1998). Unstructured interviews, however, have remained a preferred approach among employers for over a century (Buckley et al., 2000).

A burgeoning area of study has emerged in response to this gap that aims to identify factors underlying practitioners' reluctance to adopt the scientifically meritorious standardized hiring practices that have been developed. A variety of contextual factors relating to international issues (e.g., employment laws, cultural preferences; Boatman \& Erker, 2012; Ryan et al., 1999), organizational attributes (e.g., company size, industry standards; Konig et al., 2010; Lodato et al., 2011; Terpstra \& Rozell, 1997), job features (e.g., complexity, pay; Chen et al., 2008; Wilk \& Cappelli, 2003), and practical constraints (e.g., cost, time requirements; Furnham, 2008; Konig et al., 2010) have been identified as contributing to the divide. However, most research in this area has focused on individual differences among practitioners as primary antecedents.

The individual difference factors that research has identified as influencing practitioners' use of standardized employee selection practices address aspects of training and development (e.g., certification, experience; Lodato et al., 2011), cognitive processes (e.g., experiential versus analytical thinking; Chen et al., 2008), and lay beliefs about personnel selection (Slaughter \& Kausel, 2014). These beliefs commonly concern the effectiveness of hiring practices for identifying candidates with the greatest potential for success (Diab et al., 2011; Terpstra, 1996), legal defensibility (Furnham, 2008; Konig et al., 2010), and the favorability of applicant reactions to selection procedures (Dipboye, 1997; Lievens \& De Paepe, 2004). Researchers' choice of which beliefs to study has been largely guided by the presupposi-

Corresponding author:

Kevin P. Nolan

Email: kevin.p.nolan@hofstra.edu 
tion that practitioners' use of hiring methods is motived by their desire to pursue the same goals for personnel selection as their employing organizations. However, there is evidence to suggest that practitioners' use of employee selection methods is also motived by their desire to fulfill their own personal wants and needs (e.g., autonomy, power; Chen et al., 2008; Nolan \& Highhouse, 2014; Nolan, Langhammer, $\&$ Salter, 2016), and to avoid threats to their professional standing (Nolan, Carter, \& Dalal, 2016). This study offers a replication and extension of the research conducted by Nolan, Carter, and Dalal (2016), which provided initial support for the idea that "threat of technological unemployment" is an important factor contributing to practitioners' reluctance to adopt standardized hiring practices.

\section{Threat of Technological Unemployment}

The idea that evidence-based decision making can be applied to the workplace in an apolitical and interest-free fashion is an unrealistic proposition given that power and politics are fundamental issues involved with organizational change (Hodgkinson, 2012). In recognition of these social dynamics, Meehl (1986) suggested that an important factor influencing professional decision makers' adoption of standardized decision-making practices is the "threat of technological unemployment" (TOTU). TOTU refers to the notion that professional decision makers fear that using standardized decision-making practices will reduce the perceived value they provide to their employing organizations by lessening the extent to which stakeholders (e.g., supervisors) assign credit to their "expert judgment" for the outcomes of decisions. This notion is consistent with the tenets of attribution theory's discounting principle, which suggest that the presence of facilitative external factors (e.g., standardized decision-making practices) in a causal schema involving multiple sufficient causes reduces the extent to which people attribute an outcome to internal factors (e.g., human judgment; Kelley \& Michela, 1980). Research in the fields of medicine and accounting has provided support for the tenets of the discounting principle, finding that use of standardized decision-making practices reduces both the credit and the blame that is attributed to professionals for the accuracy of their predictions (Arkes et al., 2007; Lowe et al., 2002; Pezzo \& Pezzo, 2006). Initial support for TOTU as a factor influencing practitioners' adoption of standardized hiring practices was provided via two studies conducted by Nolan, Carter, and Dalal (2016).

Working from the tenets of attribution theory (Kelley, 1973), the first study conducted by Nolan et al. (2016) investigated the extent to which TOTU exists in the context of personnel selection by examining how stakeholders' perceptions of a practitioner's causality/control over a hiring decision are affected by their use of either standardized (e.g., structured interview) or nonstandardized (e.g., unstructured interview) employee selection practices. Causality and con- trol are two dimensions of attribution that respectively refer to beliefs about the extent to which an outcome resulted from factors either internal or external to an actor and the extent to which the actor was capable of changing an outcome if he/she tried (Russell, 1982). ${ }^{1}$ Use of the standardized practices was found to significantly reduce the extent to which stakeholders attributed the outcome of the hiring decision to the practitioner who was responsible for making it (i.e., standardization had a negative effect on perceptions of causality/control). Although this finding supported that TOTU exists in the context of personnel selection, the extent to which practitioners recognize the threat and it influences their use of standardized practices was still unknown. Therefore, a second study was conducted that examined the effects of using standardized or nonstandardized employee selection practices on practitioners' attribution beliefs and use intentions. Practitioners reported believing that stakeholders would perceive them as having less causality/ control over a hiring decision if standardized rather than nonstandardized practices were used to evaluate candidates, and these beliefs indirectly affected practitioners' intentions to use the practices via their concern that doing so would reduce the perceived value of their employment. Together, these findings provide initial support that TOTU is a factor that contributes to practitioners' reluctance to adopt scientifically meritorious standardized hiring practices.

As the first examination of TOTU in personnel selection, the work presented in Nolan et al. (2016) served as "proof-of-concept" research (Zhu et al., 2015). Like most research conducted in the early stages of theory development, the aim was to investigate whether an effect exists. Having observed the effect, the next steps in theory development are replication and further examination of the boundary assumptions and constraints that qualify its underlying principles (Bacharach, 1989; Highhouse, 2009). To these ends, the research presented in this manuscript aims to (a) replicate the findings of Nolan et al. (2016) using a within-subjects methodology that is more generalizable to the cognitive processes typically involved in decisions regarding use of employee selection practices, and (b) examine if techniques that are commonly used to promote standardized employee selection practices inadvertently contribute to TOTU.

\section{Joint Versus Separate Evaluation}

Nolan et al. (2016) used a between-subjects experimental design to initially examine the effect of standardization on TOTU. Practitioners reviewed the description of either a

\footnotetext{
1 The causality and control scales used in Nolan, Carter, and Dalal (2016) were highly related and, therefore, combined into a single attribution measure following the results of confirmatory factor analysis.
} 
structured or unstructured employment interview and then reported their beliefs about using it. By creating a context wherein different groups of participants reviewed the one interview format to which they were assigned, the methodology of the study elicited a mode of judgment known as separate evaluation (Bazerman et al., 1992). Decisions concerning the use/adoption of employee selection practices, however, are commonly made in contexts wherein multiple practices are simultaneously compared (Highhouse et al., 2017). The act of forming judgments about multiple options in a single context is known as joint evaluation. The cognitive processes involved in joint versus separate evaluation are meaningfully different, and changes in judgment across joint versus separate evaluation often occur (Hsee, 1996).

During separate evaluation, one option is encoded then evaluated, and judgments of utility are expressed in absolute terms. During joint evaluation, multiple options are concurrently encoded then evaluated, and judgments of utility are expressed in relative terms. Whereas the presence of alternative options frames and anchors decision making during joint evaluation, separate evaluation requires individuals to generate a decision model and determine an absolute assessment of utility. Separate evaluation is therefore considered the more difficult cognitive task, and a variety of biases associated with the task have been offered to explain why judgments vary across joint and separate modes of evaluation (Bazerman et al., 1999).

Norm theory (Ritov \& Kahneman, 1997), for example, suggests that during separate evaluation people evoke internal referents to which they compare the option that are categorically different from the alternative options presented in joint evaluation. The evaluability hypothesis (Hsee, 1996) suggests that during separate evaluation people tend to overweight option attributes that are easy to interpret in isolation and underweight attributes that are more difficult to interpret without the ability to directly compare across alternatives. The want/should proposition (Bazerman et al., 1999) suggests that during joint evaluation judgments tend to favor the option that is most justifiable because that is what people think they "should do," whereas during separate evaluation judgments tend to be more emotionally influenced by what people "want to do."

The aforementioned explanations for why judgments vary across joint versus separate evaluation highlight the value in examining the replicability of Nolan et al. (2016) using a within-subjects design wherein the effect of standardization on TOTU is examined in a context that mitigates the effects of generating inconsistent referents (e.g., comparing unstructured interviews to assessment methods other than structured interviews), underweighting attributes that are difficult to interpret in isolation (e.g., not giving adequate consideration to the ability to ask follow-up questions during unstructured interviews due to lack of awareness that this practice is prohibited during structured interviews), and letting the "want self" go unchecked in the absence of counterbalancing alternatives (e.g., focusing on the personal fulfillment associated with unstructured interviews rather than their utility for accomplishing organizational goals relative to structured interviews). Decisions concerning the use of hiring practices are often made via joint rather than separate evaluation and the within-subjects design of this study provides a more generalizable test of the cognitive processes underlying TOTU than our earlier research. Although joint evaluation may put the "want self" in check, the side-by-side comparison of interview features is likely to make salient all the ways in which standardization minimizes the contributions of human judgment. Therefore, consistent with earlier findings, we expect that interview standardization will have a negative effect on practitioners' beliefs about stakeholders' perceptions of their causality/control over the hiring process, that these beliefs will negatively relate to TOTU, which will subsequently have negative influence on use intentions. Rather than testing these relationships using the more piecemeal approach of Nolan et al. (2016), these relationships will be examined using MEMORE (Montoya \& Hayes, 2017), an SPSS macro designed to estimate mediation models for two-instance, within-subjects designs. Therefore, we more formally hypothesize that:

Hypothesis 1: Interview standardization will have a serial indirect effect on use intentions via its influence on beliefs about causality/control and TOTU.

\section{Exacerbating the Threat}

TOTU purports that practitioners' resistance to standardized hiring practices is motivated by fear that using the technically meritorious practices would lessen the perceived value their "expert judgment" affords personnel selection (Meehl, 1986). Those who advocate for standardized employee selection, however, commonly promote the use of these practices by communicating all the ways in which they are superior to practitioners' judgment. Practitioners are told that the standardized hiring practices are more reliable, better able to predict who will succeed on the job, and more legally defensible than their subjective intuition (Zhang, 2018). Perhaps these efforts have not motivated the adoption of standardized hiring practices among practitioners as expected because they inadvertently exacerbate TOTU by making salient all the reasons why the practices devalue the organizational worth of their professional judgment. Consistent with this notion, we hypothesize that:

Hypothesis 2: Promoting the structured interview by providing information about its predictive validity and/ or legal defensibility relative to the unstructured interview will exacerbate the TOTU associated with its use. 
In addition to the contents of a persuasive message, the way in which the message is framed affects how decision makers respond to it. Research on goal framing suggests that presenting a persuasive message that communicates the merits of an uncertain option in terms of its potential to prevent/avoid loss (negative frame) can have greater persuasive impact on decision makers than presenting the same message in terms of its potential to provide benefit/ gain (positive frame; Levin et al., 1998). Meyerowitz and Chaiken (1987), for example, found that women had more beneficial attitudes, intentions, and behaviors toward breast self-examination (BSE) when a persuasive message was presented in loss rather than gain frame (i.e., "You can gain [lose] several potential health benefits by spending [failing to spend] only 5 minutes each month doing BSE. Take [Don't fail to take] advantage of this opportunity" p.504). Although this effect has been demonstrated across a variety of domains, including healthcare decisions (Block \& Keller, 1995), responses to social dilemmas (Brewer \& Kramer, 1986; Fleishman, 1988), and consumer choice (Grewal et al., 1994; Homer \& Yoon, 1992), its usefulness for promoting the adoption of standardized hiring practices has been marginal and inconsistent (Hazer \& Highhouse, 1997). Information is encoded relative to its descriptive valence, with positive/negative content eliciting connections with positive/negative information in the associative memory (Levin et al., 1998). A potential explanation for why message framing has not benefited the adoption of standardized hiring practices as expected is that encoding negatively framed persuasive messages increases the salience of TOTU (i.e., negative information) associated with the practices. Consistent with this notion, we hypothesize that:

Hypothesis 3: Promoting the structured interview by presenting persuasive content in a negative rather than positive frame will exacerbate concerns about the TOTU associated with its use.

\section{METHOD}

\section{Participants}

An initial sample of $N=637$ American workers was recruited via Amazon's Mechanical Turk (MTurk), a crowdsourcing website that research suggests is a viable source of high-quality data for the social sciences (Paolacci \& Chandler, 2014). Participants who did not complete the full survey, provided incorrect responses to reading prompts embedded in the survey, exhibited careless responding, reported being professional survey takers, and/or completed the survey in less than 2 minutes were removed from the data set. Participants who reported having no experience making hiring decisions were also removed from the data set. The final sample included $N=360$ participants from over 35 occupations, who were primarily male $(59.4 \%)$ and Caucasian $(80.0 \%)$ with a mean age of 38.25 years and an average job tenure of 5.26 years. Most participants reported having a 4-year college degree $(44.1 \%)$, working for an organization with less than 500 employees $(60.6 \%)$, and having moderate experience interviewing job candidates $(M=3.43, S D=1.69)$. A more detailed description of the methodology used to arrive at the final sample is provided in the Appendix.

\section{Design and Procedure}

A 2 (interview standardization: structured, unstructured) X 3 (message frame: none, positive frame, negative frame) X 4 (information provided: none, predictive validity, legal defensibility, both predictive validity \& legal defensibility) mixed design was used in this study with interview standardization as a within-subjects factor, and the message frame and information provided as between-subjects factors (Table 1). Participants were instructed to, "Imagine yourself in the following situation... Your company has just given you permission to hire an assistant. They have provided you with two options for how you could interview job candidates. Please read the descriptions of these options carefully and tell us what you think about using each approach to evaluate the candidates." Descriptions of a structured and unstructured interview modeled after levels 4 and 1 of Huffcutt and Arthur's (1994) taxonomy of interview standardization (the same from Nolan et al., 2016) were reviewed by all participants in counterbalanced order (Table 2). The description of the structured interview included elements of both standardized data collection (i.e., question format, response scoring) and data combination (e.g., overall assessment formation), and the description of the unstructured interview included elements of both nonstandardized data collection and data combination. Based on the conditions to which participants were assigned, information was also presented concerning the utility of the structured interview relative to its unstructured counterpart (Table 3). Predictive validity information was from Huffcutt and Arthur (1994), and legal defensibility information was from Terpstra et al. (1999). After reading the materials provided, participants reported their beliefs about using the interviews to evaluate job candidates and identified the interview format they would most likely use to make the hiring decision.

\section{Measures}

All measures were from Nolan et al. (2016), and responses were made using 5-point Likert scales ( 1 = "strongly disagree", $5=$ "strongly agree"). Cronbach's $\alpha$ for the measures are presented in Table 4.

Causality/control. Participants' beliefs about the extent to which stakeholders would perceive them as having caused/having control over the hiring decision were assessed using a 6-item attributions measure, with an exam- 
ple item being, Others in the organization who knew the approach used to interview job candidates would... "think the outcome of the hiring decision reflects my ability to evaluate job candidates." Although causality and control are considered unique dimensions of attribution, consistent with the findings of Nolan et al. (2016), confirmatory factor analysis supported the use of a combined causality/control measure. $^{2}$

Threat of technological unemployment. Participants' beliefs about the extent to which the interviews pose a threat to their professional worth were assessed using a 5-item measure, with an example item being, "Consistently using this approach to make hiring decisions would lessen others' beliefs about the value I provide to my employing organization."

Use intentions. Participants' intentions to use the interviews to evaluate job candidates were assessed using a 3-item measure, with an example item being, "I would use this type of interview to evaluate job candidates."

Interview preference. Participants' preferred approach to interviewing job candidates was operationalized as the interview format for which they reported the greatest use intentions.

TABLE 1.

Study Design

\begin{tabular}{|c|c|c|c|}
\hline Condition & Target stimuli & Information provided & Information frame \\
\hline A & $\begin{array}{l}\text { Unstructured interview \& } \\
\text { structured interview }\end{array}$ & No information & No information \\
\hline B & $\begin{array}{l}\text { Unstructured interview \& } \\
\text { structured interview }\end{array}$ & Predictive validity & Positive frame \\
\hline $\mathrm{C}$ & $\begin{array}{l}\text { Unstructured interview \& } \\
\text { structured interview }\end{array}$ & Predictive validity & Negative frame \\
\hline $\mathrm{D}$ & $\begin{array}{l}\text { Unstructured interview \& } \\
\text { structured interview }\end{array}$ & Legal defensibility & Positive frame \\
\hline $\mathrm{E}$ & $\begin{array}{l}\text { Unstructured interview \& } \\
\text { structured interview }\end{array}$ & Legal defensibility & Negative frame \\
\hline $\mathrm{F}$ & $\begin{array}{l}\text { Unstructured interview \& } \\
\text { structured interview }\end{array}$ & Both predictive validity $\&$ legal defensibility & Positive frame \\
\hline G & $\begin{array}{l}\text { Unstructured interview \& } \\
\text { structured interview }\end{array}$ & Both predictive validity $\&$ legal defensibility & Negative frame \\
\hline
\end{tabular}

TABLE 2.

Descriptions of Structured and Unstructured Interview Formats

\begin{tabular}{|c|c|}
\hline Structured interview & Unstructured interview \\
\hline $\begin{array}{l}\text { With this approach, you would use a structured interview } \\
\text { to evaluate job candidates. The format of this interview } \\
\text { would be standardized. Interview questions would be based } \\
\text { on the results of a formal job analysis. You would ask the } \\
\text { same questions in the same order to each candidate, and } \\
\text { you would score candidates' responses to each question } \\
\text { using specially designed rating scales. Scale scores would } \\
\text { be combined mathematically to form an overall evaluation } \\
\text { of each candidate based on the information provided } \\
\text { throughout the interview. The candidate who receives the }\end{array}$ & $\begin{array}{l}\text { With this approach, you would use personalized interviews } \\
\text { to evaluate job candidates. The format of these interviews } \\
\text { would not be standardized. Instead, you would ask each } \\
\text { candidate a different set of questions based on the candidate's } \\
\text { own unique qualifications and experiences; asking follow- } \\
\text { up questions as you see fit. You would use your own expert } \\
\text { judgment to form an overall evaluation of each candidate } \\
\text { based on the information provided throughout the interview. } \\
\text { The candidate who receives the highest overall evaluation is } \\
\text { the person who would be hired. }\end{array}$ \\
\hline
\end{tabular}

2 Output for the analyses used to inform this decision are avail-

able from the corresponding author upon request. 
TABLE 3.

Information Presented by Information Frame

\begin{tabular}{|c|c|c|}
\hline & Positive frame & Negative frame \\
\hline $\begin{array}{l}\text { Predictive } \\
\text { validity }\end{array}$ & $\begin{array}{l}\text { Structured interviews generally provide a greater } \\
\text { ability to predict candidates' future job performance } \\
\text { than unstructured interviews. Whereas scores } \\
\text { on unstructured interviews have been found to } \\
\text { typically account for only } 4 \% \text { of the variance in } \\
\text { candidates' future job performance, scores on } \\
\text { structured interviews have been found to typically } \\
\text { account for } 32 \% \text { of the variance in candidates' future } \\
\text { job performance. Therefore, relative to unstructured } \\
\text { interviews, using structured interviews generally } \\
\text { provides decision makers with a } 28 \text {-percentage } \\
\text { point gain in predictive ability. }\end{array}$ & $\begin{array}{l}\text { Unstructured interviews generally provide less } \\
\text { ability to predict candidates' future job performance } \\
\text { than structured interviews. Whereas scores on } \\
\text { structured interviews have been found to typically } \\
\text { account for } 32 \% \text { of the variance in candidates' } \\
\text { future job performance, scores on unstructured } \\
\text { interviews have been found to typically account } \\
\text { for only } 4 \% \text { of the variance in candidates' job } \\
\text { performance. Therefore, relative to structured } \\
\text { interviews, using unstructured interviews generally } \\
\text { results in a } 28 \text {-percentage point loss in predictive } \\
\text { ability for decision makers. }\end{array}$ \\
\hline $\begin{array}{l}\text { Legal } \\
\text { defensibility }\end{array}$ & $\begin{array}{l}\text { Structured interviews generally provide greater } \\
\text { legal protection from lawsuits alleging hiring } \\
\text { discrimination than unstructured interviews. } \\
\text { A review of court cases found that hiring } \\
\text { discrimination lawsuits were } 10 \text { times less likely } \\
\text { to involve structured interviews than unstructured } \\
\text { interviews; and that only } 59 \% \text { of cases involving } \\
\text { unstructured interviews were found not guilty of } \\
\text { hiring discrimination whereas } 100 \% \text { of the cases } \\
\text { involving structured interviews were found not } \\
\text { guilty of hiring discrimination. Therefore, relative } \\
\text { to unstructured interviews, using structured } \\
\text { interviews generally provides decision makers with } \\
\text { a } 41 \text {-percentage point gain in legal protection. }\end{array}$ & $\begin{array}{l}\text { Unstructured interviews generally provide less } \\
\text { legal protection from lawsuits alleging hiring } \\
\text { discrimination than Structured interviews. A review } \\
\text { of court cases found that hiring discrimination } \\
\text { lawsuits were } 10 \text { times more likely to involve } \\
\text { unstructured interviews than structured interviews; } \\
\text { and that } 100 \% \text { of the cases involving structured } \\
\text { interviews were found not guilty of hiring } \\
\text { discrimination whereas only } 59 \% \text { of the cases } \\
\text { involving unstructured interviews were found } \\
\text { not guilty of hiring discrimination. Therefore, } \\
\text { relative to structured interviews, using unstructured } \\
\text { interviews generally results in a } 41 \text {-percentage } \\
\text { point loss in legal protection for decision makers. }\end{array}$ \\
\hline
\end{tabular}

\section{RESULTS}

Descriptive statistics and bivariate correlations are presented in Table 4. A series of paired-samples $t$-tests were first conducted to examine if participants' beliefs about the structured interview meaningfully differed from their beliefs about the unstructured interview. Results suggest that, overall, participants believed stakeholders (a) would perceive them has having greater causality/control with the unstructured $(M=4.17,95 \% C I[4.09,4.25])$ than structured interview $(M=2.85,95 \% C I[2.74,2.96]), t_{(359)}=17.78, p$ $<.01, d=.94$; (b) that the structured interview $(M=2.80$, $95 \% C I[2.68,2.92])$ posed a greater threat to their professional worth than the unstructured interview $(M=2.21$, $95 \% C I[2.10,2.32]), t_{(359)}=6.79, p<.01, d=.36$; and (c) that their intentions to use the unstructured interview ( $M=$ $3.28,95 \% C I[3.16,3.40])$ to evaluate job candidates were greater than their intentions to use the structured interview
$(M=2.98,95 \% C I[2.86,3.10]), t_{(359)}=2.67, p<.01, d=.14$ (Figure 1).

MEMORE (Montoya \& Hayes, 2017) was used to test the hypothesis that interview standardization would have an indirect effect on use intentions via its direct influence on beliefs about causality/control, which in turn have a direct influence on TOTU (Figure 2). Results suggest a significant overall serial indirect effect, Effect $=-.60$, Bootstrapped $95 \% C I[-.85,-.42]$, wherein interview standardization decreased beliefs about causality/control, Coefficient $=-1.33$, 95\%CI [-1.47, -1.18], which increased TOTU, Coefficient $=-.55,95 \% C I[-.66,-.44]$, which subsequently decreased use intentions, Coefficient $=-.82,95 \% C I[-.95,-.70]$ (Table 5 ). The magnitude of the serial indirect effect was assessed in two ways. First, the ratio of the indirect effect to the total effect (Preacher \& Kelley, 2011) suggests that $63.81 \%$ of the total effect is accounted for by the serial indirect effect of standardization on use intentions through perceive cau- 
TABLE 4.

Descriptive Statistics and Bivariate Correlations

\begin{tabular}{|c|c|c|c|c|c|c|c|c|c|}
\hline Interview type & Measure & $\alpha$ & $M(S D)$ & 1 & 2 & 3 & 4 & 5 & 6 \\
\hline 1. Structured & Causality & .92 & $2.85(1.08)$ & - & & & & & \\
\hline 2. Structured & Threat & .93 & $2.80(1.15)$ & $-.33^{*}$ & - & & & & \\
\hline 3. Structured & Use intentions & .86 & $2.98(1.20)$ & $.41^{*}$ & $-.51^{*}$ & - & & & \\
\hline 4. Unstructured & Causality & .89 & $4.17(.75)$ & $-.17 *$ & .03 & $-.16^{*}$ & - & & \\
\hline 5. Unstructured & Threat & .82 & $2.21(1.06)$ & $.32 *$ & -.10 & $.43^{*}$ & $-.42 *$ & - & \\
\hline 6. Unstructured & Use intentions & .82 & $3.28(1.14)$ & $-.26^{*}$ & $.38^{*}$ & $-.76^{*}$ & $.26^{*}$ & $-.51^{*}$ & - \\
\hline
\end{tabular}

Note. ${ }^{*}$ indicates $p<.01$

FIGURE 1.

The effect of interview standardization on causality/control, threat of technological unemployment, and use intentions

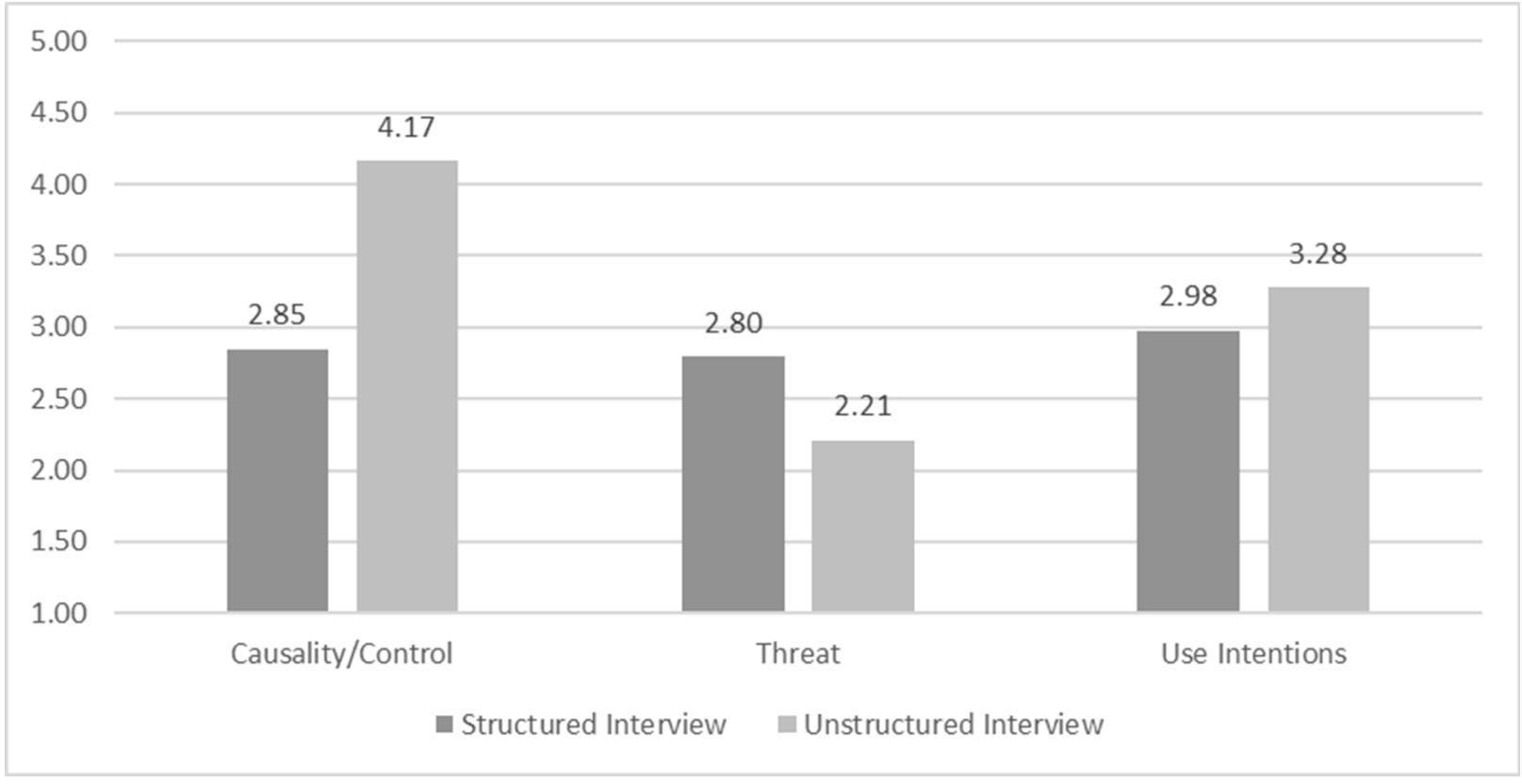

sality/control and TOTU. Second, dividing the indirect effect by the standard deviation of the outcome (Hays, 1994) suggests that use intentions decrease between a quarter to a half a standard deviation when moving from the unstructured to structured interview, through perceptions of causality/control and TOTU. ${ }^{3}$ Together, these findings suggest that the size of the serial indirect effect is moderate to large and fully support Hypothesis 1 .

A mixed-model ANOVA was conducted to examine the effects of interview standardization, information provided, and message frame on TOTU. Consistent with the findings of the MEMORE analysis, results suggest that interview standardization had a significant effect on TOTU, $F_{(1,353)}=$ 48.64, $p<.01$, partial $\eta^{2}=.12$. This main effect, however, was superseded by a significant interaction between inter- view standardization and information provided, $F_{(2,353)}=$ $3.31, p=.03$, partial $\eta^{2}=.02$ (Table 6, Figure 3). Contrary to expectation, simple effects analyses suggest that providing information about the utility of standardization did not significantly affect the TOTU associated with the structured interview regardless of which information was provided (Table 7). Providing information about predictive validi-

3 Given the within subjects nature of the study, three different estimates of the standard deviation of use intentions could be used: (1) the one for standardized use intentions, (2) the one for unstandardized use intentions, and (3) the standard deviation of the difference score (Hays, 1994). As such, we compute the partially standardized indirect effect each way with values equaling -.50 , -.53 , and -.27 , respectively. 
FIGURE 2.

Serial mediation

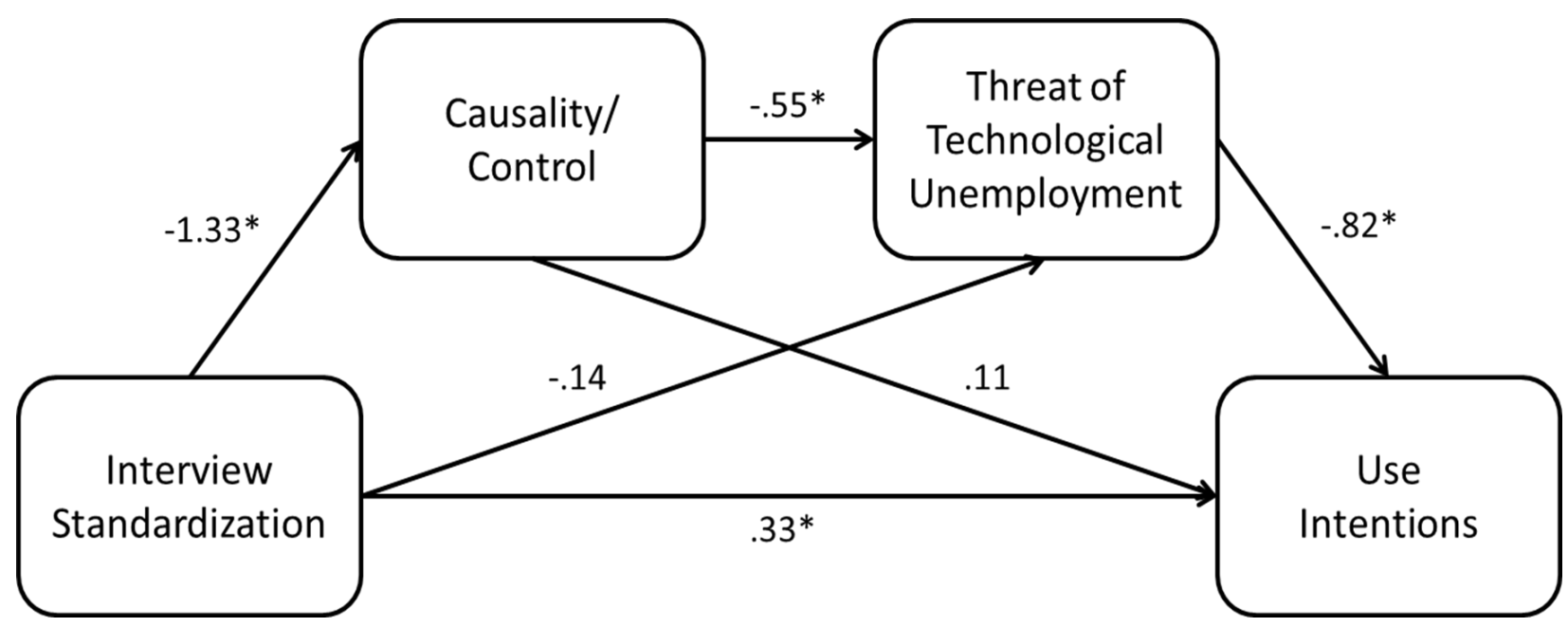

TABLE 5.

MEMORE Serial Mediation Analyses

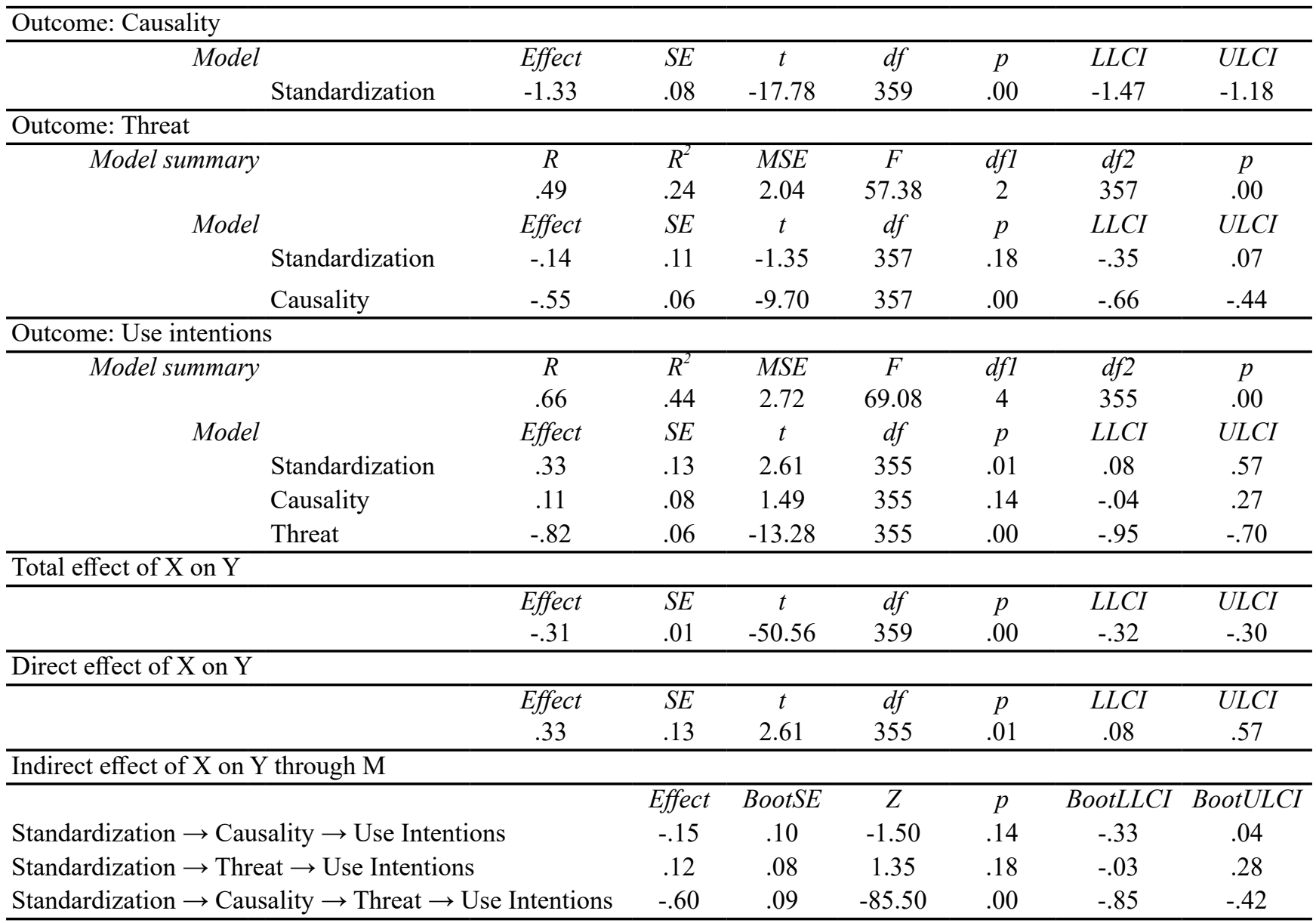


TABLE 6.

Mixed-Model ANOVA: Threat of Technological Unemployment

\begin{tabular}{|c|c|c|c|c|c|c|}
\hline \multicolumn{7}{|l|}{ Tests of within-subjects effects } \\
\hline $\begin{array}{ll}\text { Source } \\
\end{array}$ & $S S$ & $d f$ & $M S$ & $F$ & $p$ & Partial $\eta^{2}$ \\
\hline Standardization & 63.96 & 1 & 63.96 & 48.64 & .00 & .12 \\
\hline Standardization x Info Provided & 8.70 & 2 & 4.35 & 3.31 & .04 & .02 \\
\hline Standardization x Message Frame & 1.37 & 1 & 1.37 & 1.04 & .31 & .00 \\
\hline Standardization $\mathrm{x}$ Info Provided x Message Frame & 3.89 & 2 & 1.95 & 1.48 & .23 & .01 \\
\hline Error & 464.23 & 353 & 1.32 & & & \\
\hline \multicolumn{7}{|l|}{ Tests of between-subjects effects } \\
\hline Source & $S S$ & $d f$ & $M S$ & $F$ & $p$ & Partial $\eta^{2}$ \\
\hline Info provided & 2.01 & 2 & 1.01 & .93 & .40 & .01 \\
\hline Message frame & .42 & 1 & .42 & .39 & .53 & .00 \\
\hline Info Provided x Message Frame & 1.68 & 2 & .84 & .77 & .46 & .00 \\
\hline Error & 382.65 & 353 & 1.08 & & & \\
\hline
\end{tabular}

FIGURE 3.

The effects of interview standardization and information provided on threat of technological unemployment

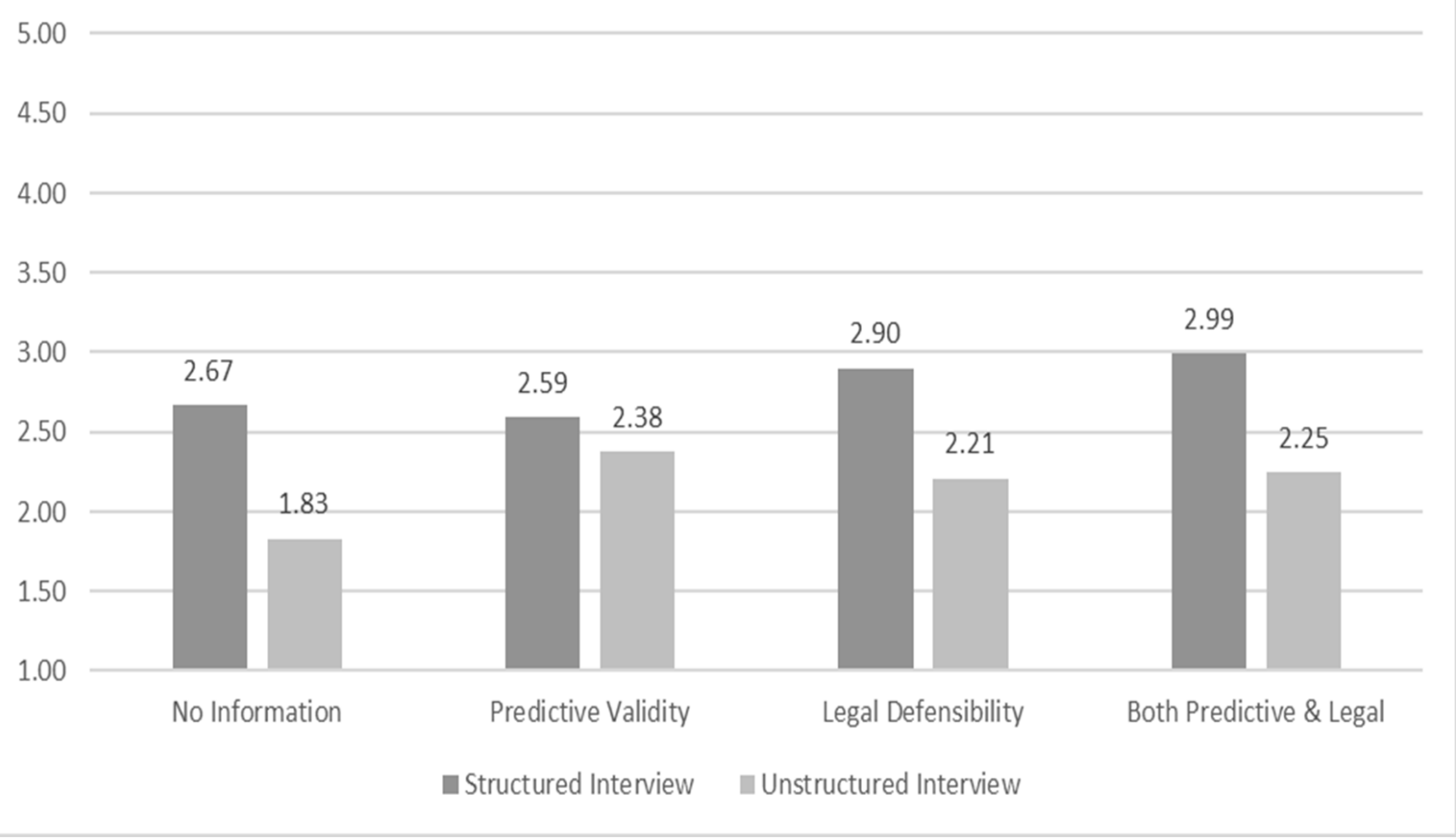


ty did, however, significantly increase TOTU associated with the unstructured interview $(M=2.38,95 \% C I[2.15$, $2.60])$ relative to the condition wherein no information was provided $(M=1.83,95 \% C I[1.57,2.09])$. This increase resulted in a condition wherein the TOTU associated with the structured interview $(M=2.59,95 \% C I[2.38,2.80])$ was not significantly different from the threat associated with the unstructured interview. These results do not support Hypotheses 2 and 3 .

Although not formally hypothesized, a mixed-model ANOVA was conducted to examine the effects of information provided and message frame on practitioners' intentions to use the interview formats. Results suggest that, on average, practitioners' intentions to use the unstructured interview $(M=3.28,95 \% C I[3.16,3.40])$ were significantly greater than their intentions to use the structured interview $(M=2.98,95 \% C I[2.86,3.10]), F_{(1,353)}=10.67, p<.01$, partial $\eta^{2}=.03$, with the effects of information provided, $F_{(2,353)}=.87, p=.42$, partial $\eta^{2}=.01$, and message frame, $F_{(1,353)}=2.20, p=.14$, partial $\eta^{2}=.01$, being nonsignificant. The percentage of practitioners within each condition that preferred the structured interview (Figure 4), however, suggests that the ways in which standardization was promoted may have meaningfully impacted practitioners' relative use intentions. A series of $Z$-tests for independent proportions was conducted using the Sidak correction for family-wise alpha inflation to explore differences among the conditions concerning the percentages of practitioners preferring the structured interview (Table 8). Results suggest that relative to the condition wherein no information promoting standardization was presented $(35.85 \%)$, practitioners reported greater preference for the structured interview when information about predictive validity was presented in the loss frame $(60.38 \%), Z=2.53, P_{a}-P_{b}=.25, p<.01-$ the same condition wherein TOTU associated with the structured and unstructured interviews was commensurate.

\section{DISCUSSION}

This study aimed to further develop the theory of TOTU in personnel selection by replicating the findings of Nolan et al. (2016) using a within-subjects methodology that is more generalizable to the cognitive processes typically involved in decisions concerning use of employee selection practices and examining if techniques that are commonly used to promote standardized employee selection inadvertently exacerbate TOTU. In having practitioners review the one interview format to which they were assigned, our earlier research examined TOTU under separate evaluation. Decisions concerning the adoption of standardized hiring practices, however, often occur in contexts wherein practices are simultaneously evaluated under joint evaluation. Because the cognitive processes involved in joint versus separate evaluation are meaningfully different, examining TOTU using a within-subjects design wherein practitioners reviewed both a structured and unstructured interview afforded greater generalizability to the cognitive processes underlying the phenomenon of interest (Highhouse, 2009).

Consistent with the findings of Nolan et al. (2016), practitioners believed that stakeholders would perceive them as having less causality/control over the hiring decision if the structured rather than unstructured interview was used to evaluate candidates, and these attribution beliefs influenced their intentions to use the practices via concerns about the perceived value of their employment. These findings replicate the results of our earlier research and extend them by using a methodology that mitigated biases commonly associated with separate evaluation that could have influenced the observed effects. For example, whereas the internal referents that practitioners generated to evaluate the interview to which they were assigned in the earlier study could have been categorically different from that method in ways other than their levels of standardization (e.g., comparing the unstructured interview to use of a personality inventory rather than a structured interview), practitioners in this study were invited to directly compare the structured and unstructured interviews. Likewise, whereas certain interview attributes may have been underweighted by practitioners in the earlier study because they were difficult to interpret in isolation (e.g., devaluing the ability to ask personalized questions during unstructured interviews due to lack of awareness that interview questions are fully standardized in structured interviews), the side-by-side presentation of attributes in this study bolstered interpretability.

Together with the results of Nolan et al. (2016), this line of research suggests that (a) stakeholders perceive practitioners as having less causality/control over personnel selection when standardized rather than non-standardized practices are used to assess candidates, and (b) practitioners recognize the effects that using standardized practices have on stakeholders' attribution beliefs and are therefore less inclined to use them out of concern that doing so would diminish their professional worth. These findings are consistent with the theory of TOTU (Meehl, 1986) and suggest that TOTU is a factor contributing to practitioners' reluctance to adopt the scientifically meritorious standardized hiring practices that have been developed. More broadly, this research serves to provide continued support for the notion that practitioners' use of personnel selection practices is not solely motivated by their desire to pursue organizational goals (e.g., hiring for performance potential) but also their motivation to fulfill their own personal needs and desires. Greater knowledge of the personal and sociopolitical factors that influence practitioners' choice of hiring procedures, like TOTU, will be required to lessen the gap between research and practice in personnel selection.

In addition to replicating the findings of Nolan et al. 
TABLE 7.

Mixed-Model ANOVA:Threat of Technological Unemployment

95\% CI for Difference

\begin{tabular}{|c|c|c|c|c|c|c|c|}
\hline \multirow{2}{*}{$\begin{array}{l}\text { Interview } \\
\text { standardization } \\
\text { Structured }\end{array}$} & \multicolumn{2}{|c|}{ Information provided } & \multirow{2}{*}{$\frac{\text { Mean difference }}{.08}$} & \multirow{2}{*}{$\begin{array}{l}S E \\
.19\end{array}$} & \multirow{2}{*}{$\frac{p}{1.00}$} & \multirow{2}{*}{$\begin{array}{c}\text { Lower } \\
-.43\end{array}$} & \multirow{2}{*}{$\frac{\text { Upper }}{.59}$} \\
\hline & No information & Predictive Validity & & & & & \\
\hline & & Legal Defensibility & -.23 & .20 & 1.00 & -.75 & .29 \\
\hline & & Both Predictive \& Legal & -.31 & .19 & .62 & -.83 & .20 \\
\hline & Predictive validity & Legal Defensibility & -.31 & .16 & .32 & -.74 & .12 \\
\hline & & Both & -.40 & .16 & .07 & -.81 & .02 \\
\hline & Legal defensibility & Both Predictive \& Legal & -.09 & .16 & 1.00 & -.51 & .34 \\
\hline \multirow[t]{7}{*}{ Unstructured } & No information & Predictive Validity & -.55 & .18 & .01 & -1.02 & -.08 \\
\hline & & Legal Defensibility & -.38 & .18 & .22 & -.85 & .10 \\
\hline & & Both predictive \& legal & -.43 & .18 & .09 & -.90 & .04 \\
\hline & Predictive validity & Legal defensibility & .18 & .15 & 1.00 & -.22 & .57 \\
\hline & & Both predictive \& legal & .12 & .15 & 1.00 & -.27 & .50 \\
\hline & Legal defensibility & Both predictive \& legal & -.06 & .15 & 1.00 & -.45 & .34 \\
\hline & & & & & \multicolumn{3}{|c|}{ 95\% CI for Difference } \\
\hline Information provided & \multicolumn{2}{|c|}{ Standardization } & Mean difference & $S E$ & $p$ & Lower & Upper \\
\hline No information & Structured interview & Unstructured interview & .85 & .22 & .00 & .41 & 1.28 \\
\hline Predictive validity & Structured interview & Unstructured interview & .21 & .16 & .18 & -.10 & .52 \\
\hline Legal defensibility & Structured interview & Unstructured interview & .70 & .17 & .00 & .38 & 1.02 \\
\hline Both predictive \& legal & Structured interview & Unstructured interview & .73 & .16 & .00 & .41 & 1.04 \\
\hline
\end{tabular}

FIGURE 4.

The effects of interview standardization and information provided on threat of technological unemployment

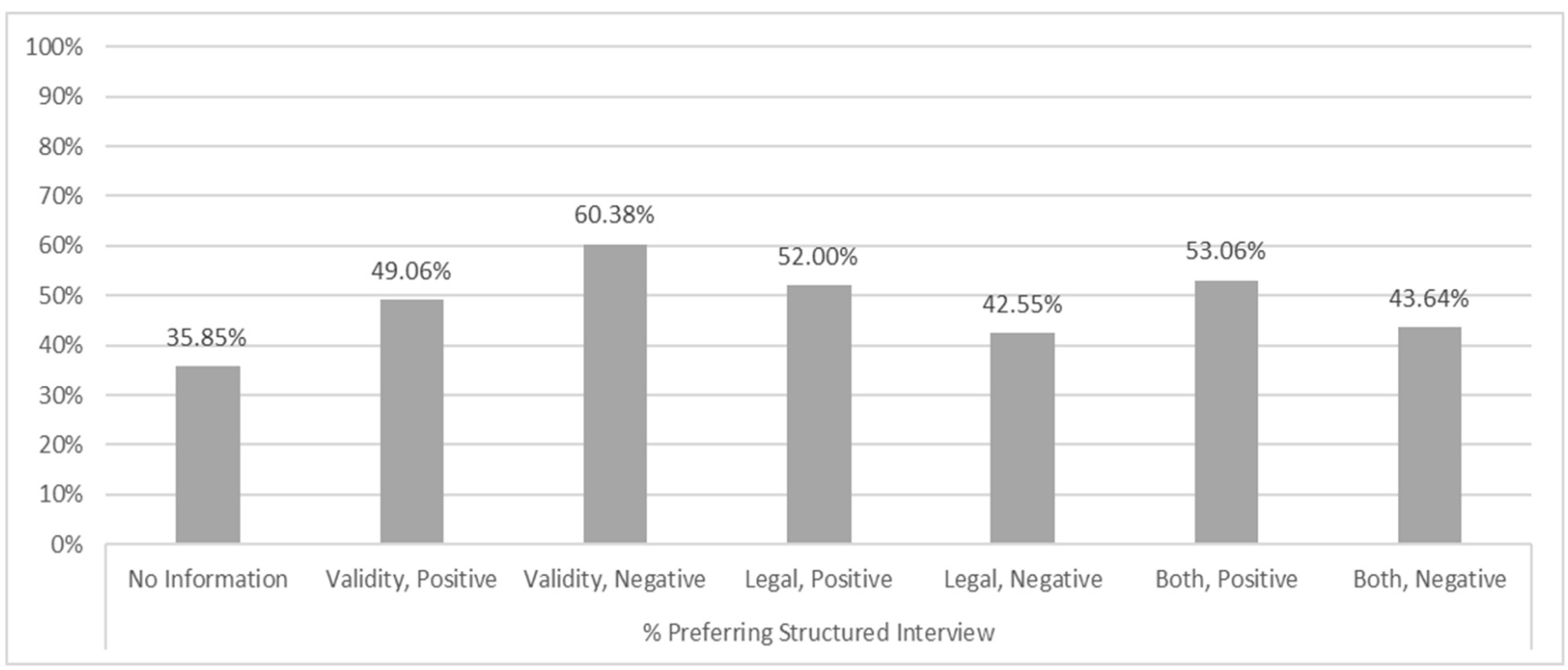


TABLE 8.

Z-Tests for Independent Proportions: Interview Preference by Condition

\begin{tabular}{|c|c|c|c|c|c|c|}
\hline \multirow[b]{2}{*}{ Condition (i) } & \multicolumn{5}{|c|}{$\%$ Preferring structured interview } & \multirow[b]{2}{*}{$p$} \\
\hline & Condition $(\mathrm{j})$ & Condition (i) & Condition (j) & Diff & $Z$ & \\
\hline \multirow[t]{6}{*}{ No information } & Validity, positive & $35.85 \%$ & $49.06 \%$ & -0.13 & -1.38 & 0.08 \\
\hline & Validity, negative & $35.85 \%$ & $60.38 \%$ & -0.25 & -2.53 & 0.01 \\
\hline & Legal, positive & $35.85 \%$ & $52.00 \%$ & -0.16 & -1.65 & 0.05 \\
\hline & Legal, negative & $35.85 \%$ & $42.55 \%$ & -0.07 & -0.69 & 0.25 \\
\hline & Both, positive & $35.85 \%$ & $53.06 \%$ & -0.17 & -1.75 & 0.04 \\
\hline & Both, negative & $35.85 \%$ & $43.64 \%$ & -0.08 & -0.83 & 0.20 \\
\hline \multirow[t]{5}{*}{ Validity, positive } & Validity, negative & $49.06 \%$ & $60.38 \%$ & -0.11 & -1.17 & 0.12 \\
\hline & Legal, positive & $49.06 \%$ & $52.00 \%$ & -0.03 & -0.30 & 0.38 \\
\hline & Legal, negative & $49.06 \%$ & $42.55 \%$ & 0.07 & 0.65 & 0.26 \\
\hline & Both, positive & $49.06 \%$ & $53.06 \%$ & 0.04 & 0.40 & 0.34 \\
\hline & Both, negative & $49.06 \%$ & $43.64 \%$ & 0.05 & 0.57 & 0.29 \\
\hline \multirow[t]{4}{*}{ Validity, negative } & Legal, positive & $60.38 \%$ & $52.00 \%$ & 0.08 & 0.86 & 0.20 \\
\hline & Legal, negative & $60.38 \%$ & $42.55 \%$ & 0.18 & 1.78 & 0.04 \\
\hline & Both, positive & $60.38 \%$ & $53.06 \%$ & 0.07 & 0.75 & 0.23 \\
\hline & Both, negative & $60.38 \%$ & $43.64 \%$ & 0.17 & 1.74 & 0.04 \\
\hline \multirow[t]{3}{*}{ Legal, positive } & Legal, negative & $52.00 \%$ & $42.55 \%$ & 0.10 & 0.93 & 0.18 \\
\hline & Both, positive & $52.00 \%$ & $53.06 \%$ & -0.01 & -0.11 & 0.46 \\
\hline & Both, negative & $52.00 \%$ & $43.64 \%$ & 0.08 & 0.86 & 0.20 \\
\hline \multirow[t]{2}{*}{ Legal, negative } & Both, positive & $42.55 \%$ & $53.06 \%$ & -0.11 & -1.03 & 0.15 \\
\hline & Both, negative & $42.55 \%$ & $43.64 \%$ & -0.01 & -0.11 & 0.46 \\
\hline Both, positive & Both, negative & $53.06 \%$ & $43.64 \%$ & 0.09 & 0.96 & 0.17 \\
\hline
\end{tabular}

(2016), this study sought to further explicate the theory of TOTU in personnel selection by examining if techniques that are commonly used to promote standardized hiring practices inadvertently exacerbate TOTU. Providing information about the superior predictive validity and legal defensibility of the standardized practice (i.e., structured interview) relative to practitioners' subjective judgment (i.e., unstructured interview) was expected to intensify the TOTU associated with its use - especially when this information was presented in loss rather than gain frame. However, providing information about the utility of the structured interview, regardless of how it was framed, did not have a significant effect on practitioners' beliefs about the TOTU associated with its use. On the one hand, this finding suggests that current techniques for communicating the utility of standardized hiring practices are not inadvertently discouraging their use. On the other, it does little to explain the relative ineffectiveness of these techniques or provide insight concerning ways to mitigate TOTU in personnel selection. A potential explanation for the null finding is that practitioners recognize that simply including an external factor (i.e., the structured interview) into stakeholders' causal schemas, regardless of the utility of that factor, is sufficient for reducing the amount of credit the stakeholders would attribute to their expert judgment (i.e., an internal factor) for the outcomes of hiring decisions. The utility information, after all, was not directly provided to stakeholders, and this explanation is consistent with the fundamental tenets of the discounting principle (Kelley \& Michela, 1980). Research examining how practitioners' attribution beliefs and TOTU are affected by providing stakeholders with information about the relative utility of standardized hiring practices would provide useful insight into the sociopolitical dynamics involved in personnel selection.

Unexpectedly, providing information about the superior predictive validity of the structured interview in loss frame significantly increased the TOTU associated with using the unstructured interview to evaluate candidates. In this condition, the TOTU for the unstructured interview was commensurate with that of the structured interview, and $60.38 \%$ of practitioners reporting preferring the structured to the unstructured interview format - a significant increase relative 
to providing no information about the utility of standardization $(35.85 \%)$. Although the finding concerning preference is consistent with the want/should proposition (Bazerman et al., 1999), which suggests that during joint evaluation judgments commonly favor the option that is most justifiable because that is what people think they "should do," research on intertemporal choice (Loewenstein \& Thaler, 1989) and the hot-cold empathy gap (Loewenstein, 2005) advises that judgments expressed under these conditions are not necessarily consistent with future behavior. Nevertheless, finding that practitioners' beliefs about the TOTU associated with the unstructured interview were affected by information about the superior predictive validity of the structured interview suggests that TOTU in personnel selection is potentially more complicated than was originally positioned in this line of research.

TOTU, in the context of personnel selection, represents practitioners' beliefs about the risk presented to their professional worth by standardized hiring practices. Providing predictive validity information in a loss frame appears to have created a Catch-22-type situation (i.e., a tricky dilemma or no-win situation) wherein risks were perceived to be associated with both using and not using the structured interview. Practitioners reported that using the structured interview to evaluate candidates would reduce stakeholders' perceptions of their causality/control over the hiring decision, which would subsequently lessen stakeholders' beliefs about their professional worth. This finding supported Hypothesis 1, which offered an explanation for TOTU that was based on the tenets of attribution theory's discounting principle (Kelley \& Michela, 1980). Here, the risk of diminished professional worth comes from incorporating an external factor (i.e., the structured interview) into stakeholders' causal schemas that would reduce the perceived value of the practitioner's internal factors (e.g., "expert" judgment) for personnel selection. When information about the superior predictive validity of the structured interview was presented in loss frame, however, practitioners also reported that not using the structured interview - in favor of the unstructured interview - would likewise lessen stakeholders' beliefs about their professional worth. Here, we posit that the risk of diminished professional worth comes from the negative effect that forgoing use of the hiring practice with greater demonstrated utility for accomplishing organizational goals would have on stakeholders' beliefs about the value the practitioners' "expert" judgment affords organizational success. Agency theory (Eisenhardt, 1989) offers a potentially useful framework for better understanding practitioners' beliefs about the various risks to professional reputation associated with using standardized and nonstandardized personnel selection practices.

Agency theory suggests that workers' goals and attitudes toward risk depend on their positions within an organization, and that people who work in higher levels of an organizational hierarchy (i.e., principals) tend to have meaningfully different goals and attitudes toward risk than people who work in lower levels of the hierarchy (i.e., agents; Eisenhardt, 1989). Finding variance in both the TOTU associated with the structured and, in the condition wherein predictive validity information was presented in loss frame, the unstructured interview suggests that the thought processes underlying TOTU may potentially differ depending on the centrality of personnel selection to one's position within an organization. For practitioners in lower level positions wherein personnel selection is a central job responsibility (e.g., recruiters), the risk presented by standardized hiring practices would likely pertain to the effect that using the practices would have on their personal goals for self-preservation/enhancement. However, for practitioners in higher-level positions wherein personnel selection is ancillary to broader responsibilities (e.g., senior management), the risk presented by the standardized practices would likely pertain to the effect that not using the practices would have on their goals for organizational success. Additional research is needed to more fully understand the cognitive processes underlying TOTU in personnel selection and how these processes vary depending on practitioners' positions within their employing organizations.

\section{Conclusions, Limitations, and Future Directions}

The findings of this study provide further support that TOTU is a factor underlying practitioners' resistance to standardized hiring practices. Future research should continue to explore the phenomenon in ways that were limited in this study. For example, Nolan et al. (2016) found that standardizing both data collection (interview question format) and data combination (response scoring) had significant main effects on TOTU. Interview standardization, however, was operationalized as a single factor in this study with the description of the structured interview characterized by both standardized data collection and data combination, and the description of the unstructured interview characterized by both nonstandardized data collection and data combination. Interview standardization was operationalized as a single factor to minimize the demand/complexity of the joint evaluation task being asked of participants in the within-subjects design (to bolster response quality) and because utility information (i.e., predictive validity, legal defensibility) was not available for each unique combination of data collection and data combination. Future research is needed to more fully understand the unique effects of data collection and data combination standardization on TOTU during joint evaluation.

Another limitation of the study concerns the way in which utility information was communicated to participants. Research suggests that communicating the effectiveness of hiring practices using approaches that avoid absolute percentages tends to improve lay interpretation of the 
information (Highhouse et al., 2017). Although information about the predictive validity and/or legal culpability associated with the structured and unstructured interviews was presented jointly to improve interpretation through providing context for evaluation, research suggests that laypeople often perceive nontraditional effect size indicators, like the binomial effect size display (BESD) and common language effect size indicator (CLES), as more understandable and useful than the more traditional indicator of percent variance accounted for (i.e., $r^{2}$ ) that was used to communicate utility in this study (Brooks et al., 2014). Consequently, the utility information presented to participants about the structured and unstructured interviews may not have been fully understood. Future research should examine if alternative ways of reporting the utility (e.g., icon arrays, expectancy charts, utility analysis, BESD, CLES) of selection practices differentially affect TOTU. Furthermore, whereas practitioners' responses to the use intentions measure were used to infer their interview preference, future research is encouraged to include forced-choice measures like those commonly found in joint evaluation studies.

The findings of this study are also limited to the effect of standardization on TOTU in the context of employment interviews. Various combination of standardized and nonstandardized hiring methods should be compared to better understand the relative levels of TOTU associated with their adoption. The effect of artificial intelligence on TOTU in personnel selection, for example, is a topic that seems particularly germane to the current climate. Perhaps most importantly, research is needed to identify ways to prevent TOTU from impeding the use of standardized employee selection practices. This will likely require greater insight into the individual differences and organizational factors that contribute to practitioners' concern. Nolan and Highhouse (2014), for example, found that incorporating practitioners' subjective judgment into the design of standardized employee selection practices increased their expectations about psychological need fulfillment and subsequent use intentions. Appropriately integrating practitioners' judgment into the design of standardized hiring practices may likewise increase beliefs about their causality/control over the selection process and thus reduce TOTU. Future research is encouraged to pursue this line of study.

\section{REFERENCES}

Arkes, H. R., Shaffer, V. A., \& Medow, M. A. (2007). Patients derogate physicians who use a computer-assisted diagnostic aid. Medical Decision Making, 27(2), 189-202.

Bacharach, S. B. (1989). Organizational theories: Some criteria for evaluation. Academy of Management Review, 14, 496-515.

Bazerman, M. H., Loewenstein, G. F., \& White, S. B. (1992). Reversals of preference in allocation decisions: Judging an alternative versus choosing among alternatives. Administrative
Science Quarterly, 37, 220-240.

Bazerman, M. H., Moore, D. A., Tenbrunsel, A. E., Wade-Benzoni, K. A., \& Blount, S. (1999). Explaining how preferences change across joint versus separate evaluation. Journal of Economic Behavior \& Organization, 39, 41-58.

Block, L. G., \& Keller, P. A. (1995). When to accentuate the negative: The effects of perceived efficacy and message framing on intentions to perform a health-related behavior. Journal of Marketing Research, 32, 192-203.

Boatman, J., \& Erker, S. (2012). Global Selection Forecast: Know More. Guess Less. Pittsburgh, PA: Developmental Dimensions International.

Brewer, M. B., \& Kramer, R. M. (1986). Choice behavior in social dilemmas: Effects of social identity, group size, and decision framing. Journal of Personality and Social Psychology, 50, 543.

Brooks, M. E., Dalal, D. K., \& Nolan, K. P. (2014). Are common language effect sizes easier to understand than traditional effect sizes? Journal of Applied Psychology, 99(2), 332-340.

Buckley, M. R., Christine Norris, A., \& Wiese, D. S. (2000). A brief history of the selection interview: May the next 100 years be more fruitful. Journal of Management History, 6, 113126.

Chen, Y. C., Tsai, W. C., \& Hu, C. (2008). The influences of interviewer-related and situational factors on interviewer reactions to high structured job interviews. International Journal of Human Resource Management, 19, 1056-1071.

Conway, J. M., Jako, R. A., \& Goodman, D. F. (1995). A meta-analysis of interrater and internal consistency reliability of selection interviews. Journal of Applied Psychology, 80, 565-579.

Diab, D. L., Pui, S., Yankelevich, M., \& Highhouse, S. (2011). Lay perceptions of selection decision aids in U.S. and non-U.S. Samples. International Journal of Selection and Assessment.

Dipboye, R. L. (1997). Structured selection interviews: Why do they work? Why are they underutilized? In N. Anderson \& P. Herriot (Eds.), International handbook of selection and assessment (pp. 455-473). New York: Wiley.

Eisenhardt, K. M. (1989). Agency theory: An assessment and review. Academy of Management Review, 14(1), 57-74.

Fleishman, J. A. (1988). The effects of decision framing and others' behavior on cooperation in a social dilemma. Journal of Conflict Resolution, 32, 162-180.

Furnham, A. (2008). HR professionals' beliefs about and knowledge of, assessment techniques and psychometric tests. International Journal of Selection and Assessment, 16, 300305.

Grewal, D., Gotlieb, J., \& Marmorstein, H. (1994). The moderating effects of message framing and source credibility on the price-perceived risk relationship. Journal of Consumer Research, 21, 145-153.

Hays, W. L. (1994). Statistics (5th Ed.). New York, NY: Hardcourt Brace College Publishers.

Hazer, J. T., \& Highhouse, S. (1997). Factors influencing managers' reactions to utility analysis: Effects of SDy method, information frame, and focal intervention. Journal of Applied Psychology, 82, 104-112.

Highhouse, S. (2008). Stubborn reliance on intuition and subjectivity in employee selection. Industrial and Organizational Psychology: Perspectives on Science and Practice, 1, 333342. 
Highhouse, S. (2009). Designing experiments that generalize. Organizational Research Methods, 12, 554-566.

Highhouse, S., Brooks, M. E., Nesnidol, S., \& Sim, S. (2017). Is a. 51 validity coefficient good? Value sensitivity for interview validity. International Journal of Selection and Assessment, 25, 383-389.

Hodgkinson, G.P. (2012). The politics of evidence-based decision making. In D. M. Rousseau (Ed.), The Oxford handbook of evidence-based management (pp. 404-419). Oxford Handbooks Online.

Homer, P. M., \& Yoon, S. G. (1992). Message framing and the interrelationships among ad-based feelings, affect, and cognition. Journal of Advertising, 21(1), 19-33.

Hsee, C. K. (1996). The evaluability hypothesis: An explanation for preference reversals between joint and separate evaluations of alternatives. Organizational Behavior and Human Decision Processes, 67, 247-257.

Huffcutt, A.I., \& Arthur, W., Jr. (1994). Hunter and Hunter (1984) revisited: Interview validity for entry-level jobs. Journal of Applied Psychology, 79, 184-190.

Huffcutt, A. I., \& Roth, P. L. (1998). Racial group differences in employment interview evaluations. Journal of applied Psychology, 83, 179-189.

Kelley, H. H. (1973). The process of causal attribution. American Psychologist, 28, 107-128.

Kelley, H. H., \& Michela, J. L. (1980). Attribution theory and research. Annual Review of Psychology, 31, 457-501.

Konig, C.J., Klehe, U., \& Berchtold, M. (2010). Reasons for being selective when choosing personnel selection procedures. International Journal of Selection and Assessment, 18, 1727.

Levin, I. P., Schneider, S. L., \& Gaeth, G. J. (1998). All frames are not created equal: A typology and critical analysis of framing effects. Organizational Behavior and Human Decision Processes, 76, 149-188.

Lievens, F., \& De Paepe, A. (2004). An empirical investigation of interviewer-related factors that discourage the use of high structure interviews. Journal of Organizational Behavior, 25, 29-46.

Lodato, M. A., Highhouse, S., \& Brooks, M. E. (2011). Predicting professional preferences for intuition-based hiring. Journal of Managerial Psychology, 26, 352-365.

Loewenstein, G. (2005). Hot-cold empathy gaps and medical decision making. Health Psychology, 24(4S), S49-S56.

Loewenstein, G., \& Thaler, R. H. (1989). Anomalies: intertemporal choice. Journal of Economic Perspectives, 3(4), 181-193

Lowe, D. J., Reckers, P. M., \& Whitecotton, S. M. (2002). The effects of decision-aid use and reliability on jurors' evaluations of auditor liability. Accounting Review, 77(1), 185-202

Meehl, P.E. (1986). Causes and effects of my disturbing little book. Journal of Personality Assessment, 50, 370-375.

Meyerowitz, B. E., \& Chaiken, S. (1987). The effect of message framing on breast self-examination attitudes, intentions, and behavior. Journal of Personality and Social Psychology, 52, 500-510.

Montoya, A. K., \& Hayes, A. F. (2017). Two-condition within-participant statistical mediation analysis: A path-analytic framework. Psychological Methods, 22, 6-27.

Nolan, K. P., Carter, N. T., \& Dalal, D. K. (2016). Threat of technological unemployment: Are hiring managers discounted for using standardized employee selection practices? Personnel Assessment and Decisions, 2, 30-47.

Nolan, K.P., \& Highhouse, S. (2014). Need for autonomy and resistance to standardized employee selection practices. Human Performance, 27, 328-346.

Nolan, K. P., Langhammer, K., \& Salter, N. P. (2016). Evaluating fit in employee selection: Beliefs about how, when, and why. Consulting Psychology Journal: Practice and Research, 68, 222-251.

Paolacci, G., \& Chandler, J. (2014). Inside the Turk: understanding mechanical turk as a participant pool. Current Directions in Psychological Science, 23, 184-188.

Pezzo, M. V., \& Pezzo, S. P. (2006). Physician evaluation after medical errors: Does having a computer decision aid help or hurt in hindsight? Medical Decision Making, 26(1), 48-56

Preacher, K. J., \& Kelley, K. (2011). Effect size measures for mediation models: Quantitative strategies for communicating indirect effects. Psychological methods, 16(2), 93.

Ritov, I., \& Kahneman, D. (1997). How people value the environment: Attitudes versus economic values. In M. H. Bazerman, D. M. Messick, A. E. Tenbrunsel, \& K. A. Wade-Benzoni (Eds.), Environment, ethics, and behavior: The psychology of environmental valuation and degradation (pp. 33-51). The New Lexington Press.

Russell, D. (1982). The Causal Dimension Scale: A measure of how individuals perceive causes. Journal of Personality and Social Psychology, 42(6), 1137-1145.

Ryan, A. M., McFarland, L., Baron, H., \& Page, R. (1999). An international look at selection practices: Nation and culture as explanations for variability in practice. Personnel Psychology, 52, 359-391.

Rynes, S. L. (2012). The research-practice gap in industrial/organizational psychology and related fields: Challenges and potential solutions. In S. W. J. Kozlowski (Ed.), The Oxford handbook of industrial-organizational psychology. New York, NY: Oxford University Press.

Slaughter, J. E., \& Kausel, E. E. (2014). Employee selection decisions. In S. Highhouse, R. S. Dalal, \& E. Salas (Eds.), Judgment and decision making at work. New York, NY: Routledge.

Terpstra, D. E. (1996). The search for effective methods. HR Focus, 73, 16-17.

Terpstra, D. E., Mohamed, A. A., \& Kethley, R. B. (1999). An analysis of federal court cases involving nine selection devices. International Journal of Selection and Assessment, 7, 26-34.

Terpstra, D. E., \& Rozell, E. J. (1997). Why some potentially effective staffing practices are seldom used. Public Personnel Management, 26, 483-495.

Wilk, S. L., \& Cappelli, P. (2003). Understanding the determinants of employer use of selection methods. Personnel Psychology, 56, 103-124.

Zhang, D. C. (2018). Art of the sale: Recommendations for sharing research with mainstream media and senior leaders. Industrial and Organizational Psychology, 11(4), 589-593.

Zhu, X., Barnes-Farrell, J. L., \& Dalal, D. K. (2015). Stop apologizing for your samples, start embracing them. Industrial and Organizational Psychology, 8, 228-232.

RECEIVED 05/20/19 ACCEPTED 12/27/19 


\section{Appendix}

The sampling methodology targeted people with hiring experience by posting a HIT (Human Intelligence Task) on MTurk, which was solely available to users in the USA, that specifically requested that only "workers" who were employed - not as professional survey takers - and had experience making hiring decisions participate in the study (i.e., complete the HIT). This resulted in an initial sample of $N=637$ participants.

Four reading prompts were embedded in the survey, each requesting participants to respond to items using a unique point on the response scale (i.e., 3, 4, 1, 2). Participants were excluded from the sample if they provided an incorrect response to any of the four prompts. This resulted in 172 participants being eliminated, with the criteria serving to exclude careless responders and those who did not complete the entire survey. $(N=465)$

In the demographics section (i.e., the last section) of the survey, participants were asked, "How much experience do you have making hiring decisions?" If participants selected the "No experience" response option, they were excluded from the sample. This resulted in 97 more participants being eliminated. $(N=368)$

In the demographics section of the survey, participants were also asked, "Which of the following most accurately describes your job title?" If participants selected the "Unemployed" or "Professional Survey Taker" response options, they were excluded from the sample. This resulted in 6 more participants being eliminated. $(N=362)$

The duration of time participants spent completing the survey was also recorded. Participants who spent less than 2 minutes completing the survey were excluded from the sample as this was deemed an unreasonably short amount of time spent on task. This resulted in two more participants being eliminated. $(N=360)$

Using this approach, only those participants who were (a) employed, not as professional survey takers; (b) had experience making hiring decisions; (c) completed the full survey in a reasonable amount of time; and (d) correctly answered each of the four reading prompts embedded in the survey were included in the final sample. 